(C2020. This manuscript version is made available under the CC-BY-NC-ND 4.0 license http://creativecommons.org/licenses/by-nc-nd/4.0/

\title{
Synthesis, structure and gas adsorption properties of coordination polymers based on mixed imidazole-containing ligands and carboxylate ligands
}

Jiang-Lin Zhao ${ }^{\mathrm{a}, 1}$, Chong Wu ${ }^{\mathrm{b}, 1}$, Carl Redshaw ${ }^{\mathrm{c}}$ and Zongwen Jin*,a

\footnotetext{
${ }^{a}$ Institute of Biomedical \& Health Engineering, Shenzhen Institutes of Advanced Technology, Chinese Academy of Sciences, 1068 Xueyuan Avenue, Shenzhen 518055, China.Email: zw.jin@siat.ac.cn (Z. Jin)

${ }^{b}$ college of Pharmacy, Guizhou University of Traditional Chinese Medicine, Guiyang 550025, People's Republic of China.

${ }^{c}$ Department of Chemistry, University of Hull, Hull HU6 7RX, UK.

${ }^{1}$ Jiang-Lin Zhao and Chong Wu contributed equally to this work.
}

\begin{abstract}
Herein, we report the synthesis of two novel coordination polymers using a combination of imidazole-containing ligands, namely 1,3,5-tris((1H-imidazol-1-yl)methyl)benzene $\quad\left(\mathrm{L}^{1}\right) \quad$ and 3,3',5,5'-tetra(1H-imidazol-1-yl)-1,1'-biphenyl $\left(\mathrm{L}^{2}\right)$ and a carboxylate ligand derived from 4,4'-biphenyldicarboxylic acid $\left(\mathrm{H}_{2} \mathrm{BPDC}\right)$. The structures of the two coordination polymers $\left[\mathrm{Ni}\left(\mathrm{L}^{1}\right)(\mathrm{BPDC})\right] \cdot 2 \mathrm{H}_{2} \mathrm{O}\left(\mathbf{1} \cdot 2 \mathrm{H}_{2} \mathrm{O}\right)$, which exhibits a 2 -fold interpenetrated $3 \mathrm{D} \rightarrow 3 \mathrm{D}$ architecture, and $\left\{\left[\mathrm{Co}\left(\mathrm{CH}_{3} \mathrm{OH}\right)_{2}\left(\mathrm{~L}^{2}\right)_{0.5}(\mathrm{BPDC})\right]\right.$ possessing a $2 \mathrm{D}$ framework, have been determined. Moreover, the gas adsorption properties of $\mathbf{1}$ and $\mathbf{2}$ have been investigated.
\end{abstract}

\section{Introduction}

Metal organic frameworks (MOFs) have emerged as one of the most intriguing subjects in material science not only because of their fascinating topological structures but also due to their high surface areas and tunable pore size. ${ }^{[1-3]}$ After years of development, studies on MOFs have been expanded from mere synthesis to extensive applications in areas such as gas storage and separation, catalysis, energy storage, luminescent materials, drug delivery, magnetic materials and so on. ${ }^{[4-15]}$ Although quantities of MOFs have been successfully synthesized, controllable synthesis and fully predicting the structure remains a challenge.

According to previous studies, not only the nature of the building blocks (the 
linkers and metal ion/clusters nodes) but also synthetic factors such as temperature, solvent, $\mathrm{pH}$, templates and so on can play a pivotal role in the synthesis of MOFs. ${ }^{[16-25]}$ Among these influencing factors, rational design and choice of organic ligands are critical in the construction of MOFs. ${ }^{[26]}$ Furthermore, in addition to using a single ligand as a building block, a mixed-ligand strategy is often employed as well because it can combine the characters of different ligands and thus be beneficial for the construction of more complicated architectures. ${ }^{[27-29]}$

As typical ligands with a strong capability of coordination, both imidazole-containing ligands and carboxylate ligands are the most commonly used organic linkers in the synthesis of MOFs. Herein, we report the synthesis of two novel coordination polymers by using the combination of imidazole-containing ligands and carboxylate ligands with the formula of $\left[\mathrm{Ni}\left(\mathrm{L}^{1}\right)(\mathrm{BPDC})\right] \cdot 2 \mathrm{H}_{2} \mathrm{O}$ (1) and $\left\{\left[\mathrm{Co}\left(\mathrm{CH}_{3} \mathrm{OH}\right)_{2}\left(\mathrm{~L}^{2}\right)_{0.5}(\mathrm{BPDC})\right](2)\left(\mathrm{L}^{1}=1,3,5\right.\right.$-tris $((1 \mathrm{H}$-imidazol-1-yl)methyl $)$ benzene; $\mathrm{L}^{2}=3,3^{\prime}, 5,5^{\prime}$-tetra(1H-imidazol-1-yl)-1,1'-biphenyl; $\quad \mathrm{H}_{2} \mathrm{BPDC}=$ 4,4'-biphenyldicarboxylic acid, Scheme 1). The structures of these two complexes have been determined, with complex 1 exhibiting a 2-fold interpenetrated $3 \mathrm{D} \rightarrow 3 \mathrm{D}$ architecture, while complex 2 exhibits a 2D framework, where the carboxylate ligand BPDC $^{2-}$ adopts a $\kappa^{1}-\kappa^{1}-\mu_{2}$-BPDC mode to connect two $\mathrm{Co}(\mathbb{I})$ ions and are nearly parallel to the $2 \mathrm{D} \mathrm{L}^{2}-\mathrm{Co}$ layers. Moreover, the thermal stability and sorption properties of the complexes have been investigated.
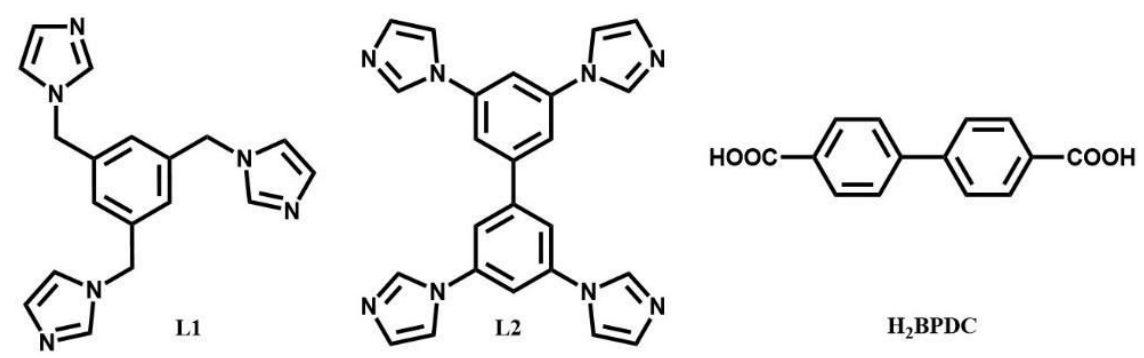

Scheme 1. Structures of $\mathrm{L}^{1}, \mathrm{~L}^{2}$ and $\mathrm{H}_{2} \mathrm{BPDC}$.

\section{Experimental Section}

\section{Materials and methods}

The organic ligands $\mathbf{L}^{1}$ and $\mathbf{L}^{2}$ were synthesized by following a previously published procedure. $^{[30,31]}$ All other commercially available chemicals and solvents are of reagent grade and used without further purification. Elemental analyses for $\mathrm{C}, \mathrm{H}$ and $\mathrm{N}$ were performed on a Perkin-Elmer 240C Elemental Analyzer at the analysis center of Nanjing University. FT-IR spectra were recorded in the range of $400-4000 \mathrm{~cm}^{-1}$ 
on a Bruker Vector22 FT-IR spectrophotometer using KBr pellets. Powder X-ray diffraction (PXRD) measurements were carried out on a Bruker D8 Advance X-ray diffractometer using $\mathrm{Cu}-\mathrm{K} \alpha$ radiation $(\lambda=1.5418 \AA)$, in which the X-ray tube was operated at $40 \mathrm{kV}$ and $40 \mathrm{~mA}$. Thermal gravimetric analyses (TGA) were taken on a Mettler-Toledo (TGA/DSC1) thermal analyzer under the $\mathrm{N}_{2}$ atmosphere with a heating rate of $10{ }^{\circ} \mathrm{C} \mathrm{min}^{-1}$. The fluorescence spectra were measured on a Perkin Elmer LS-55 fluorescence spectrophotometer.

Synthesis of $\left[\mathbf{N i}\left(\mathbf{L}^{1}\right)(\mathbf{B P D C})\right] \cdot \mathbf{2} \mathrm{H}_{2} \mathrm{O}$ (1). A mixture of $\mathrm{L}^{1}$ (16 $\left.\mathrm{mg}, 0.05 \mathrm{mmol}\right)$, $\mathrm{NiCl}_{2} \cdot 6 \mathrm{H}_{2} \mathrm{O}(47.5 \mathrm{mg}, 0.2 \mathrm{mmol}), \mathrm{N}, \mathrm{N}$-dimethylformamide (DMF, $2 \mathrm{~mL}$ ) and $\mathrm{H}_{2} \mathrm{O}(8$ $\mathrm{mL}$ ) was sealed in Teflon-lined stainless steel container and heated at $90{ }^{\circ} \mathrm{C}$ for 4320 min. After being cooled to room temperature, green block crystals of 1 were obtained in $32 \%$ yield. Anal. Calcd for $\mathrm{C}_{32} \mathrm{H}_{30} \mathrm{NiN}_{6} \mathrm{O}_{6}: \mathrm{C} 58.82, \mathrm{H} 4.60, \mathrm{~N} 12.86 \%$. Found: $\mathrm{C}$ 58.91, H 4.55, N 12.67\%. IR (KBr pellet, $\mathrm{cm}^{-1}$ ): 3062 (w), 1742 (m), 1710 (s), 1646 (s), 1480 (m), 1461 (w), 1433 (m), 1403 (s), 1220 (s), 1109 (s), 1108 (w), 1002 (w), $956(\mathrm{w}), 922(\mathrm{w}), 861(\mathrm{w}), 802(\mathrm{~m}), 711(\mathrm{~m}), 734(\mathrm{w}), 602(\mathrm{w}), 580(\mathrm{w}), 502(\mathrm{~m}), 489$ (m).

Synthesis of $\left\{\left[\mathrm{Co}\left(\mathrm{CH}_{3} \mathrm{OH}\right)_{2}\left(\mathrm{~L}^{2}\right)_{0.5}(\mathrm{BPDC})\right]\right.$ (2). A mixture of $\mathrm{L}^{2}(10.5 \mathrm{mg}, 0.25$ mmol), $\mathrm{Co}\left(\mathrm{NO}_{3}\right)_{2} \cdot 6 \mathrm{H}_{2} \mathrm{O}$ (29.1 mg, $\left.1.0 \mathrm{mmol}\right), N, N$-dimethylformamide (DMF, $2 \mathrm{~mL}$ ), $\mathrm{CH}_{3} \mathrm{OH}(4 \mathrm{~mL})$ and $\mathrm{H}_{2} \mathrm{O}(4 \mathrm{~mL})$ was sealed in Teflon-lined stainless steel container and heated at $120{ }^{\circ} \mathrm{C}$ for $4320 \mathrm{~min}$. After being cooled to room temperature, pink block crystals of 2 were obtained in $29 \%$ yield. Anal. Calcd for $\mathrm{C}_{28} \mathrm{H}_{23} \mathrm{CoN}_{4} \mathrm{O}_{6}$ : C 58.95, H 4.06, N 9.82 \%. Found: C 58.91, H 4.12, N 9.76\%. IR (KBr pellet, $\mathrm{cm}^{-1}$ ): 3066 (w), 1782 (m), 1700 (s), 1622 (s), 1610 (m), 1555 (w), 1492 (m), 1465 (s), 1362 (s), 1355 (s), $1236(\mathrm{w}), 1101(\mathrm{w}), 1051$ (w), 1022 (w), 958 (m), 874 (w), 865 (m), 735 (m), $732(\mathrm{w}), 681(\mathrm{w}), 602(\mathrm{w})$, 584(m), $516(\mathrm{~m})$.

\section{X-Ray crystallography}

The crystallographic data collections for $\mathbf{1}$ and $\mathbf{2}$ were carried out on a Bruker Smart Apex II CCD area-detector diffractometer with graphite-monochromated Mo K $\alpha$ radiation $(\lambda=0.71073 \AA)$ at $293(2) \mathrm{K}$ using the $\omega$-scan technique. The diffraction data were integrated by using the $S A I N T$ program ${ }^{[32]}$, which was also used for the intensity corrections for the Lorentz and polarization effects. Semi-empirical absorption correction was applied using the $S A D A B S$ program ${ }^{[33]}$. The structures were solved by direct methods and all the non-hydrogen atoms were refined anisotropically on $F^{2}$ by the full-matrix least-squares technique using the SHELXL-97 crystallographic 
software package ${ }^{[34]}$. All non-hydrogen atoms were refined anisotropically. Hydrogen atoms of the water molecules were located from the difference Fourier maps and refined with restraint of the $\mathrm{O}-\mathrm{H}$ and $\mathrm{H} \cdots \mathrm{H}$ distance ( $0.96 \AA$ and $1.52 \AA$, respectively). Other hydrogen atoms were introduced at the calculated positions. The details of the crystal parameters, data collection and refinements for the complexes are summarized in Table 1, and selected bond lengths and angles with their estimated standard deviations are listed in Table 2. CCDC NO. 2012894 (1), and 2012895 (2).

Table 1. Crystal Data and Structure Refinements for complexes $\mathbf{1}$ - 2.

\begin{tabular}{lcc}
\hline Complex & $\mathbf{1}$ & $\mathbf{2}$ \\
\hline Formula & $\mathrm{C}_{32} \mathrm{H}_{30} \mathrm{NiN}_{6} \mathrm{O}_{6}$ & $\mathrm{C}_{28} \mathrm{H}_{23} \mathrm{CoN}_{4} \mathrm{O}_{6}$ \\
Formula weight & 653.33 & 570.43 \\
$\mathrm{~T}(\mathrm{~K})$ & $293(2)$ & $293(2)$ \\
Crystal system & Monoclinic & Orthorhombic \\
Space group & $P 2_{1} / n$ & $F d d d$ \\
$a(\AA)$ & $14.970(4)$ & $15.653(2)$ \\
$b(\AA)$ & $12.756(3)$ & $23.218(4)$ \\
$c(\AA)$ & $16.397(4)$ & $30.639(5)$ \\
$\alpha\left({ }^{\circ}\right)$ & 90 & 90 \\
$\beta\left({ }^{\circ}\right)$ & $107.900(3)$ & 90 \\
$\gamma\left({ }^{\circ}\right)$ & 90 & 90 \\
$V\left(\AA^{3}\right)$ & $2979.6(13)$ & $11135(3)$ \\
$Z$ & 4 & 16 \\
$D_{\text {calc }}\left(\mathrm{g} \mathrm{cm}^{-3}\right)$ & 1.456 & 1.361 \\
$\left.\mu(\mathrm{mm})^{-1}\right)$ & 0.707 & 0.664 \\
$F(000)$ & 1360 & 6860 \\
Reflections collected & 15673 & 13480 \\
Unique reflections & 5854 & 2498 \\
Goodness-of-fit on $F^{2}$ & 1.028 & 1.331 \\
$R_{1}$, & 0.0805 & 0.1188 \\
$w R_{2}[\mathrm{I}>2 \sigma(I)]^{\mathrm{a}, \mathrm{b}}$ & 0.1207 & 0.2170 \\
$R_{1}$, & 0.1337 & 0.1242 \\
$w R_{2}[$ all data $]$ & 0.1349 & 0.2196 \\
${ }^{\circ} R_{1}=\Sigma|| F_{\mathrm{o}}|-| F_{\mathrm{c}}|| \Sigma\left|F_{\mathrm{o}}\right| \cdot{ }^{b} w R_{2}=\left|\Sigma w\left(\left|F_{\mathrm{o}}\right|^{2}-\left|F_{\mathrm{c}}\right|^{2}\right)\right| \Sigma\left|w\left(F_{\mathrm{o}}\right)^{2}\right|^{1 / 2}$, where $w=\mathrm{m}=1 /\left[\sigma^{2}\left(F_{\mathrm{o}}^{2}\right)+(a P)^{2}+b P\right]$. \\
$\mathrm{P}=\left(F_{\mathrm{o}}{ }^{2}+2 F_{\mathrm{c}}{ }^{2}\right) / 3$ & & \\
\hline
\end{tabular}

Table 2. Selected bond lengths $(\AA)$ and angles $\left(^{\circ}\right)$ for complexes $\mathbf{1}$ and $\mathbf{2}$.

\begin{tabular}{llll}
\hline $\mathrm{Ni}(1)-\mathrm{O}(4) \# 1$ & $2.037(3)$ & $\mathrm{Ni}(1)-\mathrm{N}(2) \# 3$ & $2.086(4)$ \\
$\mathrm{Ni}(1)-\mathrm{N}(6)$ & $2.059(4)$ & $\mathrm{Ni}(1)-\mathrm{O}(2)$ & $2.106(3)$ \\
$\mathrm{Ni}(1)-\mathrm{N}(4) \# 2$ & $2.074(4)$ & $\mathrm{Ni}(1)-\mathrm{O}(1)$ & $2.200(3)$ \\
$\mathrm{O}(4) \# 1-\mathrm{Ni}(1)-\mathrm{N}(6)$ & $89.12(14)$ & $\mathrm{O}(4) \# 1-\mathrm{Ni}(1)-\mathrm{O}(2)$ & $174.35(13)$ \\
$\mathrm{O}(4) \# 1-\mathrm{Ni}(1)-\mathrm{N}(4) \# 2$ & $86.84(14)$ & $\mathrm{N}(6)-\mathrm{Ni}(1)-\mathrm{O}(2)$ & $95.25(14)$ \\
$\mathrm{N}(6)-\mathrm{Ni}(1)-\mathrm{N}(4) \# 2$ & $94.94(15)$ & $\mathrm{N}(4) \# 2-\mathrm{Ni}(1)-\mathrm{O}(2)$ & $89.22(13)$
\end{tabular}




\begin{tabular}{llll}
$\mathrm{O}(4) \# 1-\mathrm{Ni}(1)-\mathrm{N}(2) \# 3$ & $94.06(14)$ & $\mathrm{N}(2) \# 3-\mathrm{Ni}(1)-\mathrm{O}(2)$ & $89.39(14)$ \\
$\mathrm{N}(6)-\mathrm{Ni}(1)-\mathrm{N}(2) \# 3$ & $91.65(15)$ & $\mathrm{O}(4) \# 1-\mathrm{Ni}(1)-\mathrm{O}(1)$ & $114.26(13)$ \\
$\mathrm{N}(4) \# 2-\mathrm{Ni}(1)-\mathrm{N}(2) \# 3$ & $173.36(15)$ & $\mathrm{N}(6)-\mathrm{Ni}(1)-\mathrm{O}(1)$ & $156.62(13)$ \\
$\mathrm{N}(2) \# 3-\mathrm{Ni}(1)-\mathrm{O}(1)$ & $86.65(13)$ & $\mathrm{N}(4) \# 2-\mathrm{Ni}(1)-\mathrm{O}(1)$ & $86.98(13)$ \\
$\mathrm{O}(2)-\mathrm{Ni}(1)-\mathrm{O}(1)$ & $61.43(12)$ & & \\
\hline & & $\mathbf{2}$ & \\
\hline $\mathrm{Co}(1)-\mathrm{N}(1) \# 1$ & $2.108(6)$ & $\mathrm{Co}(1)-\mathrm{O}(3)$ & $2.110(6)$ \\
$\mathrm{Co}(1)-\mathrm{N}(1)$ & $2.108(6)$ & $\mathrm{Co}(1)-\mathrm{O}(1)$ & $2.116(5)$ \\
$\mathrm{Co}(1)-\mathrm{O}(3) \# 1$ & $2.110(6)$ & $\mathrm{Co}(1)-\mathrm{O}(1) \# 1$ & $2.116(5)$ \\
$\mathrm{N}(1) \# 1-\mathrm{Co}(1)-\mathrm{N}(1)$ & $93.3(3)$ & $\mathrm{O}(3) \# 1-\mathrm{Co}(1)-\mathrm{O}(1)$ & $87.8(2)$ \\
$\mathrm{N}(1) \# 1-\mathrm{Co}(1)-\mathrm{O}(3) \# 1$ & $88.2(3)$ & $\mathrm{O}(3)-\mathrm{Co}(1)-\mathrm{O}(1)$ & $88.1(3)$ \\
$\mathrm{N}(1)-\mathrm{Co}(1)-\mathrm{O}(3) \# 1$ & $178.1(3)$ & $\mathrm{N}(1) \# 1-\mathrm{Co}(1)-\mathrm{O}(1) \# 1$ & $93.3(2)$ \\
$\mathrm{N}(1) \# 1-\mathrm{Co}(1)-\mathrm{O}(3)$ & $178.1(3)$ & $\mathrm{N}(1)-\mathrm{Co}(1)-\mathrm{O}(1) \# 1$ & $90.6(3)$ \\
$\mathrm{N}(1)-\mathrm{Co}(1)-\mathrm{O}(3)$ & $88.2(3)$ & $\mathrm{O}(3) \# 1-\mathrm{Co}(1)-\mathrm{O}(1) \# 1$ & $88.1(3)$ \\
$\mathrm{O}(3) \# 1-\mathrm{Co}(1)-\mathrm{O}(3)$ & $90.3(4)$ & $\mathrm{O}(3)-\mathrm{Co}(1)-\mathrm{O}(1) \# 1$ & $87.8(2)$ \\
$\mathrm{N}(1) \# 1-\mathrm{Co}(1)-\mathrm{O}(1)$ & $90.6(3)$ & $\mathrm{O}(1)-\mathrm{Co}(1)-\mathrm{O}(1) \# 1$ & $174.3(3)$ \\
$\mathrm{N}(1)-\mathrm{Co}(1)-\mathrm{O}(1)$ & $93.3(2)$ & & \\
\hline
\end{tabular}

Symmetry transformations used to generate equivalent atoms: \#1 $x-1, y, z ; \# 2 x-1 / 2,-y+3 / 2, z-1 / 2$; $\# 3 \mathrm{x}, \mathrm{y}+1, \mathrm{z}$ for $\mathbf{1}$; $\# 1-\mathrm{x}+1 / 4,-\mathrm{y}+1 / 4, \mathrm{z}$ for $\mathbf{2}$.

\section{Results and discussion}

\section{Crystal structure description}

Crystal Structure of $\left[\mathrm{Ni}\left(\mathrm{L}^{1}\right)(\mathrm{BPDC})\right] \cdot 2 \mathrm{H}_{2} \mathrm{O}$ (1). Single-crystal X-ray diffraction analysis reveals that $\mathbf{1}$ crystallizes in the monoclinic crystal system with the space group of $P 2_{1} / n$. Each asymmetric unit consists of one $\mathrm{Ni}(\mathrm{II})$ cation, one $\mathrm{L}^{1}$ ligand, one BPDC $^{2-}$ anion and two free water molecules. As depicted in Figure 1a, the Ni1 atom adopts an octahedral coordination geometry surrounded by three nitrogen atoms (N2\#1, N4\#2, N6) from three distinct imidazole-containing ligands $\mathrm{L}^{1}$ and three oxygen atoms $(\mathrm{O} 1, \mathrm{O} 2, \mathrm{O} 4 \# 3)$ from two adjacent carboxylate ligands. The Ni-O and Ni-N bond lengths are in the range of 2.037(3) - 2.200(3) and 2.059(4) - 2.086(4) $\AA$, respectively. Further inspection of the structure of 1 reveals that each $\mathrm{L}^{1}$ binds to three $\mathrm{Ni}(\mathrm{II})$ atoms to form a two-dimensional (2D) networks (Figure 1b) by ignoring the connection between $\mathrm{Ni}(\mathrm{II})$ and $\mathrm{BPDC}^{2-}$ anions. Moreover, the carboxylate groups in each BPDC $^{2-}$ adopt a $\left(\kappa^{1}\right)-\left(\kappa^{2}\right)-\mu_{2}$-BPDC coordination mode to connect two $\mathrm{Ni}(\mathrm{II})$ atoms, which pillar the $2 \mathrm{D} \mathrm{L}^{1}-\mathrm{Ni}$ networks to give a 3D framework (Figure 1c). The most striking feature of compound $\mathbf{1}$ is that a pair of identical $3 \mathrm{D}$ frameworks is 
interlocked with each other by non-covalent interactions (Figure 1e), which thus directly result in the formation of a 2 -fold interpenetrated $3 \mathrm{D} \rightarrow 3 \mathrm{D}$ architecture (Figure 1d). From a topological viewpoint, the $\mathrm{L}^{1}$ ligands connect three $\mathrm{Ni}(\mathrm{II})$ ions, and thus can be regarded as 3-connected nodes, while the $\mathrm{BPDC}^{2-}$ links two Ni(II) and can be simplified to 2-connected nodes. Meanwhile, Ni(II) can be treated as 5-connectors since $\mathrm{Ni}(\mathrm{II})$ links three L ligands and two $\mathrm{BPDC}^{2-}$. According to the simplification rule, the overall structure of $\mathbf{1}$ is a 3,5-connected 2-nodal 3D net with stoichiometry (3-c)(5-c), as shown in Figure 1g and 1h. The Point (Schlăfli) symbol for the $3 \mathrm{D}$ net is $\left\{6^{3}\right\}\left\{6^{9} .8\right\}$ calculated by the TOPOS program ${ }^{[35,36]}$.

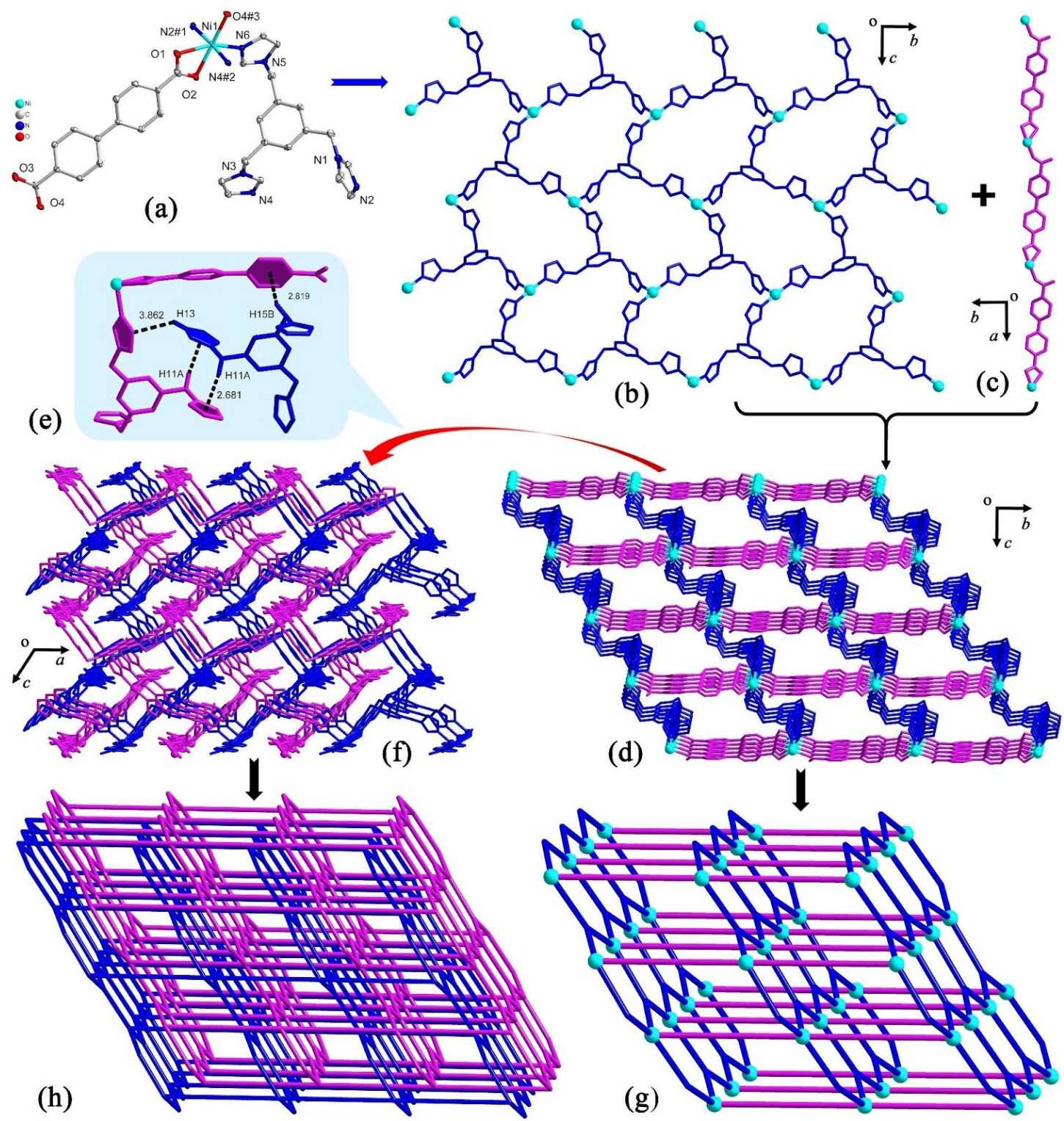

Figure 1. (a) The coordination environment of $\mathrm{Ni}(\mathrm{II})$ in 1 with the ellipsoids drawn at the $30 \%$ probability level. The hydrogen atoms are omitted for clarity. Symmetric code: \#1: $x, 1+y, z ; \# 2:-0.5+x, 1.5-y,-0.5+z ; \# 3:-1+x, y$, z. (b) The 2D L ${ }^{1}-$ Ni networks and (c) the 1D BPDC-Co chains in 1. (d) The 3D framework pillared by BPDC ${ }^{2-}$. (e) The detailed non-covalent interactions between the interpenetrated $3 \mathrm{D}$ framework. (f) The final 2-fold 
interpenetrated structure of $\mathbf{1}$. Schematic representation of (3,5)-connected single 3D framework (g) and (h) 2-fold interpenetration framework of $\mathbf{1}$.

Crystal Structure of $\left.\left\{\left[\mathrm{Co}\left(\mathrm{CH}_{3} \mathrm{OH}\right)_{2}\left(\mathrm{~L}^{2}\right)_{0.5}(\mathrm{BPDC})\right]\right)\right\}$ (2). Single-crystal X-ray diffraction analysis reveals that $\mathbf{2}$ crystallizes in the orthorhombic crystal system with space group of Fddd. Each asymmetric unit contains one half of the molecular formula of complex 2. As depicted in Figure 2a, Co1 atom adopts an octahedral coordination geometry surrounded by two nitrogen atoms (N1, N1\#1) from two adjacent imidazole-containing ligands $\mathrm{L}^{2}$ and four oxygen atoms $(\mathrm{O} 1, \mathrm{O} 1 \# 1, \mathrm{O} 3$, O3\#1) from two distinct carboxylate ligands and two coordinated methanol molecules. The Co-N bond length is 2.106(7) $\AA$ and the Co-O bond lengths are 2.110(7) and 2.115(5) $\AA$, respectively. In the structure of 2, each $\mathrm{L}^{2 \mathrm{~s}}$ connects four $\mathrm{Co}(\mathrm{II})$ ions and these four $\mathrm{Co}$ (II) ions are almost in the same plane, which thus results in the formation of a two-dimensional (2D) $\mathrm{L}^{2}$-Co networks (Figure 2b) by ignoring the connection between $\mathrm{Co}(\mathrm{II})$ and $\mathrm{BPDC}^{2-}$ anions. Furthermore, it is worth noting that although the carboxylate groups in each $\mathrm{BPDC}^{2-}$ connect two $\mathrm{Co}$ (II) atoms in $\left(\kappa^{1}\right)-\left(\kappa^{1}\right)-\mu_{2}$-BPDC coordination mode to give 1D BPDC-Co chains (Figure $2 \mathrm{c}$ ), these chains are parallel to the $2 \mathrm{D} \mathrm{L}^{2}$-Co networks and are located at both two sides of the plane, which then generates the 2D sandwich layer structure (Figure 2d). Finally, the 3D supramolecular architecture of $\mathbf{2}$ (Figure 2f) is obtained through the noncovalent interlayer interactions including hydrogen interactions $(2.315 \AA)$ and $\pi \ldots \pi$ interactions $(3.768 \AA)^{[37]}$ between $\mathrm{L}^{2}$ and $\mathrm{BPDC}^{2-}$ (Figure 2e). According to the simplification rule, the overall structure of 2 is 4,4-connected 2-nodal 3D net with stoichiometry (4-c) $)_{2}(4-c)$, as shown in Figure. $2 \mathbf{g}$ and $\mathbf{2 h}$. 


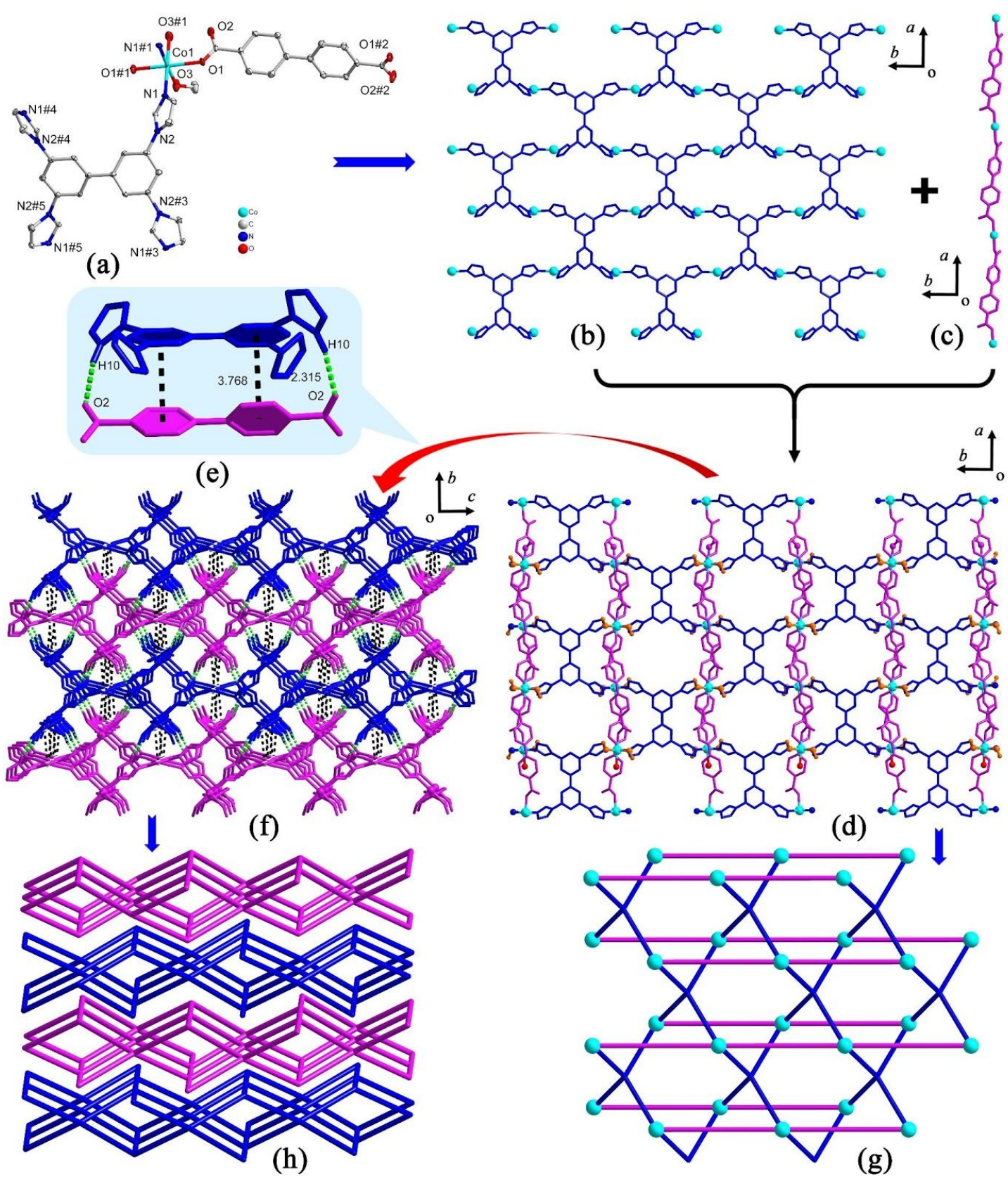

Figure 2. (a) The coordination environment of Co(II) in $\mathbf{2}$ with the ellipsoids drawn at the $30 \%$ probability level, the hydrogen atoms are omitted for clarity. Symmetric code: \#1: 0.25-x, 0.25-y, z; \#2: -0.75-x, 0.25-y, z; \#3: x, 0.75-y, 0.75-z; \#4: 0.75-x, y, 0.75-z; \#5: 0.75-x, 0.75-y, z. (b) The 2D L L $^{2}$-Co(II) networks and (c) the 1D BPDC-Co(II) chains in 2. (d) The 2D sandwich $\mathrm{L}^{2}$-BPDC-Co(II) layers in 2. (e) The non-covalent interlayer interactions. (f) The final 3D supramolecular structure of 2. Schematic representation of $(4,4)$-connected single 2D framework (g) and (h) 3D framework by non-covalent of 2.

\section{Powder X-Ray Diffraction (PXRD) and Stability Studies}

The bulk-phase purity of the synthesized samples of $\mathbf{1}$ and $\mathbf{2}$ was examined by using PXRD measurements. As depicted in Figure 3, the results of PXRD analysis revealed that the peak positions of the obtained crystalline samples of $\mathbf{1}$ and $\mathbf{2}$ were consistent with the simulated ones generated from the single-crystal diffraction data, confirming the phase purity of the synthesized samples. Differences between the patterns can be 
attributed to differences in the wavelength ( $\mathrm{Cu}$ radiation for PXRD, Mo for SCXRD) of the incident X-radiation. Difficulties associated with the characterization of as synthesized MOFs have been discussed recently. ${ }^{[38]}$

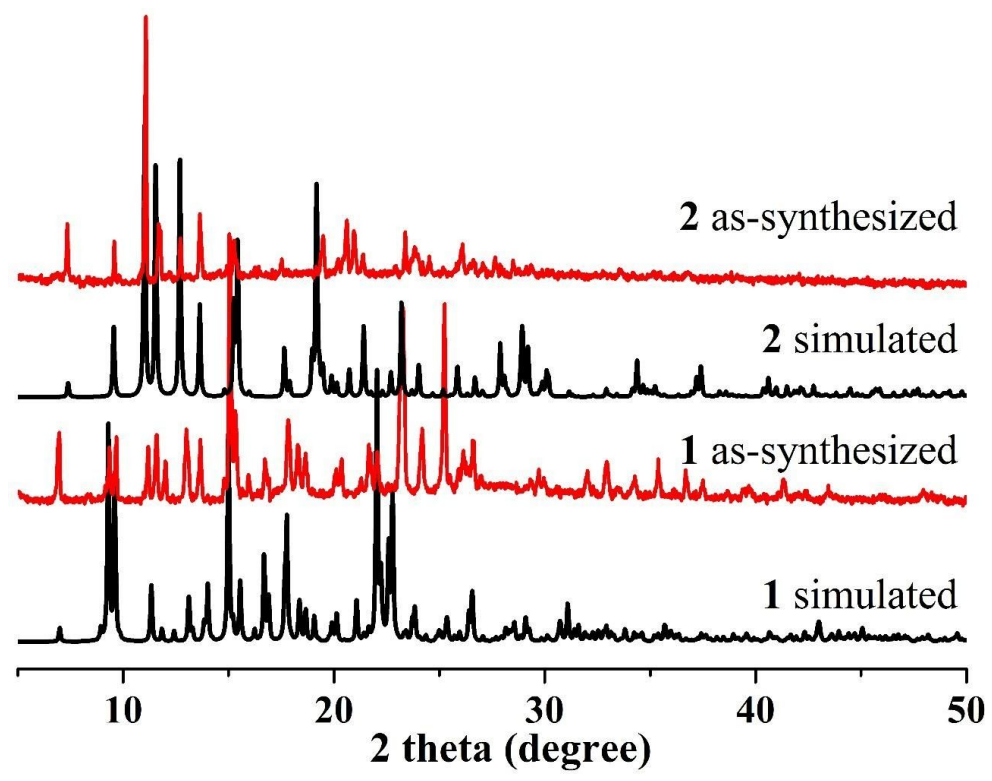

Figure 3. PXRD patterns for 1-2 under ambient conditions: simulated (black) and as-synthesized (red).

The thermal stability of $\mathbf{1}$ and $\mathbf{2}$ was investigated by thermogravimetric analysis (TGA). As shown in Figure 4, compound 1 displays a weight loss of $5.7 \%$ in the range of $30-160^{\circ}$, suggesting the release of the free water molecules (calcd 5.52\%) and its framework begins decomposing at about 415. Complex 2 exhibits a weight loss of $11.2 \%$ from 30 to $150^{\circ}$, corresponding to the release of the free and coordinated water molecules and the structure remains stable up to $390^{\circ}$. 


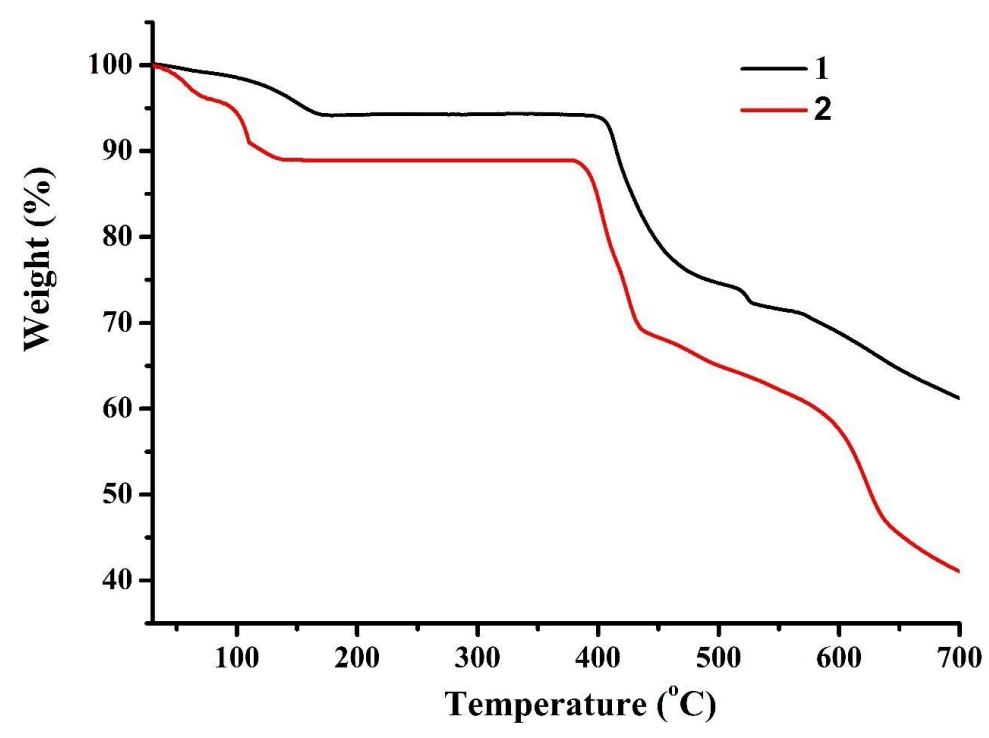

Figure 4. The TGA curves of 1 and 2.

\section{Gas adsorption properties}

The results of the structural analyses show that there are solvent molecules in the complexes 1 and 2. Further TGA and PXRD measurements were carried out to ascertain the thermal stability of the complexes for subsequent sorption property investigations, and it was found that the solvent molecules in $\mathbf{1}$ and $\mathbf{2}$ can be removed completely by heating to give dehydrated samples of 1' and 2' without destroying the structure (Figure S2 and S3), respectively. The vapor adsorption behavior of 1' and 2' was investigated with $\mathrm{N}_{2}, \mathrm{H}_{2} \mathrm{O}$ and $\mathrm{MeOH}$. As shown in Figure 5, the sorption curves of $\mathrm{N}_{2}$ at $77 \mathrm{~K}$ for $\mathbf{1}$ ' and 2' suggest only surface adsorption. ${ }^{[39-41]}$ The final value of the $\mathrm{H}_{2} \mathrm{O}$ uptake is about $83 \mathrm{~cm}^{3} \mathrm{~g}^{-1}\left(67 \mathrm{mg} \mathrm{g}^{-1}\right)$ corresponding to $2.3 \mathrm{H}_{2} \mathrm{O}$ molecules per formula unit, while the uptake of $\mathrm{MeOH}$ is about $49 \mathrm{~cm}^{3} \mathrm{~g}^{-1}\left(70 \mathrm{mg} \mathrm{g}^{-1}\right)$ equivalent to $1.1 \mathrm{MeOH}$ molecules per formula unit of $\mathbf{1}^{\prime}$. As for the adsorption of $\mathbf{2}$ ', the uptake is about $41 \mathrm{~cm}^{3} \mathrm{~g}^{-1}\left(33 \mathrm{mg} \mathrm{g}^{-1}\right)$ for $\mathrm{H}_{2} \mathrm{O}$ and $91 \mathrm{~cm}^{3} \mathrm{~g}^{-1}\left(130 \mathrm{mg} \mathrm{g}^{-1}\right)$ for $\mathrm{MeOH}$ (Figure 5b), corresponding to $0.98 \mathrm{H}_{2} \mathrm{O}, 2.19$ and $\mathrm{MeOH}$ molecules per formula unit, respectively. Based on above results, it is observed that the complex 1' has the adsorption abilities of $\mathrm{H}_{2} \mathrm{O}$ over $\mathrm{MeOH}$ vapor, while 2' exhibits larger uptake for $\mathrm{MeOH}$ than water, the reason can be attributed to the kinetic diameter of $\mathrm{MeOH}$ (3.6 $-4.0 \AA)$ is higher than that of water (2.6 -2.9 $\AA$ ). Thus, most of the reported MOFs show larger water sorption than $\mathrm{MeOH}$. 

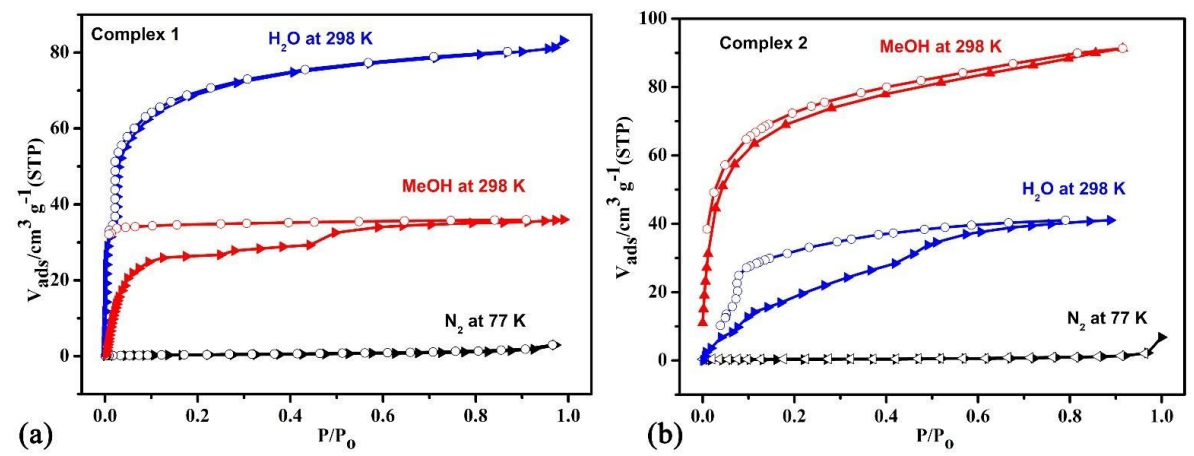

Figure 5. $\mathrm{N}_{2}, \mathrm{MeOH}$ and $\mathrm{H}_{2} \mathrm{O}$ sorption isotherms for 1' (a) and 2' (b) (filled shape $\boldsymbol{\nabla}$, adsorption; open shape $\mathrm{O}$, desorption).

\section{Conclusion}

In summary, two novel coordination polymers have been synthesized successfully using the mixed-ligand strategy by employing imidazole-containing ligands and carboxylate ligands under the solvothermal conditions. Both of the structure of complexes 1 and 2 exhibit 3D coordination framework architecture with different topologies. With the assistance of non-covalent interactions, 1 exhibits a 2 -fold interpenetrated 3D structure, while complex 2 possesses a 2D framework. The results imply that both auxiliary ligands and anions can impact on the structure of the coordination polymers. The results of gas adsorption demonstrate that the frameworks show unique adsorption properties towards $\mathrm{H}_{2} \mathrm{O}$ and $\mathrm{MeOH}$, implying a potential application in vapor separation.

\section{Acknowledgements}

This work was supported by the Basic Research Program of Shenzhen (JCYJ20190812151405298, JCYJ20170413153034718 $\&$ JCYJ20170818164040422), CAS Key Laboratory of Health Informatics (2011DP173015) and CR thanks the EPSRC for an Overseas Travel Grant (EP/R023816/1).

\section{Supplementary materials}

CCDC NO. 2012894 - 2012895 contain the supplementary crystallographic data for this paper. The data can be obtained free of charge via www.ccdc.cam.ac.uk/data_request/cif (or from The Cambridge Crystallographic Data Centre, 12, Union Road, Cambridge CB2 1EZ, UK; fax: +44 1223336 033; e-mail: deposit@ccdc.cam.ac.uk). 


\section{Conflicts of interest}

There are no conflicts to declare.

\section{Reference}

[1] H. Sung Cho, H. Deng, K. Miyasaka, Z. Dong, M. Cho, A. V. Neimark, J. Ku Kang, O. M. Yaghi, O. Terasaki, Nature, 527 (2015) 503-507.

[2] D. C. Mayer, A. Manzi, R. Medishetty, B. Winkler, C. Schneider, G. Kieslich, A. Pothig, J. Feldmann, R.A. Fischer, J. Am. Chem. Soc., 141 (2019), 11594-11602.

[3] T. Kundu, M. Wahiduzzaman, B.B. Shah, G. Maurin, D. Zhao, Angew Chem. Int. Ed., 58 (2019) 8073-8077.

[4] M. D. Allendorf, C. A. Bauer, R. K. Bhakta, R. J. Houk, Chem. Soc. Rev., 38 (2009) 1330-1352.

[5] J. R. Li, R. J. Kuppler, H. C. Zhou, Chem. Soc. Rev., 38 (2009) 1477-1504.

[6] B. Chen, S. Xiang, G. Qian, Acc. Chem. Res., 43 (2010) 1115-1124.

[7] A. Morozan, F. Jaouen, Energ. Environ. Sci., 5 (2012) 9269 - 9290.

[8] N. Stock, S. Biswas, Chem. Rev., 112 (2012) 933-969.

[9] H. Furukawa, K.E. Cordova, M. O'Keeffe, O.M. Yaghi, Science, 341 (2013) 1230444.

[10] S.-L. Li, Q. Xu, Energ. Environ. Sci., 6 (2013) 1656.

[11] Z. Hu, B.J. Deibert, J. Li, Chem. Soc. Rev., 43 (2014) 5815-5840.

[12] Weigang Lu, Zhangwen Wei, Zhi-Yuan Gu, Tian-Fu Liu, Jinhee Park, Jihye Park, Jian Tian, Muwei Zhang, Qiang Zhang, Thomas Gentle III, M. Boscha, H.-C. Zhou, Chem. Soc. Rev., 43 (2014) 5561-5593.

[13] Y. Cui, B. Li, H. He, W. Zhou, B. Chen, G. Qian, Acc. Chem. Res., 49 (2016) 483-493.

[14] A. Dhakshinamoorthy, A.M. Asiri, H. Garcia, Angew Chem. Int. Ed., 55 (2016) 5414-5445.

[15] B. Li, H.M. Wen, Y. Cui, W. Zhou, G. Qian, B. Chen, Adv. Mater., 28 (2016) 8819-8860.

[16] R. Custelcean, M.G. Gorbunova, J. Am. Chem. Soc., 127 (2005) 16362-16363.

[17] L. Luo, K. Chen, Q. Liu, Y. Lu, T.-a. Okamura, G.-C. Lv, Y. Zhao, W.-Y. Sun, Cryst. Growth Des., 13 (2013) 2312-2321.

[18] D. M. Shin, I. S. Lee, Y. K. Chung, Inorg. Chem., 42 (2003) 8838-8846. 
[19] C. N. Morrison, A. K. Powell, G. E. Kostakis, Cryst. Growth Des., 11 (2011) 3653-3662.

[20] N. Ishii, J. Mamiya, T. Ikeda, F.M. Winnik, Chem. Commun., 47 (2011) 1267-1269.

[21] Y.B. Go, X. Wang, E.V. Anokhina, A.J. Jacobson, Inorg. Chem., 44 (2005) $8265-8271$.

[22] S.M. Fang, Q. Zhang, M. Hu, E.C. Sanudo, M. Du, C.S. Liu, Inorg. Chem., 49 (2010) 9617-9626.

[23] C. Tedesco, L. Erra, I. Immediata, C. Gaeta, M. Brunelli, M. Merlini, C. Meneghini, P. Pattison, P. Neri, Cryst. Growth Des., 10 (2010) 1527-1533.

[24] (a) V. Lozan, G. Makhloufi, V. Druta, P. Bourosh, V. Ch. Kravtsov, N. Marangoci, C. Heering, C. Janiak, Inorg. Chim. Acta, 506 (2020) 119500. (b) I. Voda, G. Makhloufi, V. Druta, V. Lozan, S. Shova, P. Bourosh, V. Kravtsov, C. Janiak, Inorg. Chim. Acta 482 (2018) 526-534. (c) I. Voda, G. Makhloufi, V. Lozan, S. Shova, C. Heering, C. Janiak, Inorg. Chim. Acta, 455 (2017) 118-131.

[25] (a) Y.-L. Xu, Y. Liu, X.-H. Liu, Y. Zhao, Z. -L. Wang, W.-Y. Sun, Isr. J. Chem. 59 (2019) 267. (b) Y. Deng, Z.-Y. Yao, P. Wang, Y. Zhao, Y.-S. Kang, M. Azam, S. I. Al-Resayes, W.-Y. Sun, RSC Advances, 7 (2017) 44639-44646. (c) Y. Deng, Y. Zhao, P. Wang, Z.-Y. Yao, X.-D. Zhang, W.-Y. Sun, Micropor. Mesopor. Mater., 241 (2017) 192-201.

[26] D. Zhao, D.J. Timmons, D. Yuan, H.C. Zhou, Acc Chem Res, 44 (2011) 123-133.

[27] A.D. Burrows, CrystEngComm., 13 (2011).

[28] D.-M. Chen, N. Xu, X.-H. Qiu, P. Cheng, Cryst. Growth Des., 15 (2015) 961-965.

[29] L.-L. Zhai, Y. Zhao, L. Luo, P. Wang, Q. Liu, K. Chen, W.-Y. Sun, Micropor. Mesopor. Mat., 187 (2014) 86-93.

[30] H.-K. Liu, W.-Y. Sun, D.-J. Ma, K.-B. Yu, W.-X. Tang, Chem. Commun. (2000) 591.

[31] L. Luo, P. Wang, G. -C. Xu, Q. Liu, K. Chen, Y. Lu, Y. Zhao, W. -Y. Sun, Cryst. Growth Des., 12 (2012) 2634.

[32] SAINT, Program for Data Extraction and Reduction, Bruker AXS, Inc., Madison, WI, 2001. 
[33] G. M. Sheldrick, SADABS, Program for Empirical Adsorption Correction of Area Detector Data. University of Gottingen, Gottingen, Germany, 2003.

[34] (a) G. M. Sheldrick, SHELXS-97, Program for the Crystal Structure Solution, University of Gottingen, Gottingen, Germany, 1997; (b) G. M. Sheldrick, SHELXL-97, Program for the Crystal Structure Solution, University of Gottingen, Gottingen, Germany, 1997.

[35] V. A. Blatov, IUCr CompComm Newsl. 7 (2006) 4.

[36] V. A. Blatov, TOPOS, a Multipurpose Crystallochemical Analysis with the Program Package, Samara State University, Russia, 2009.

[37] C. Janiak, J. Chem. Soc., Dalton Trans. (2000) 3885-3896.

[38] (a) E. J. Carrington, I. J. Vitórica-Yrezábel and L. Brammer, Acta Cryst. Sect. B, B70 (2014) 404. (b) A. A. Yakovenko, Z. Wei, M. Wriedt, J.-R. Li, G. J. Halder and H.-C. Zhou, Cryst. Growth Des. 14 (2014) 5397.

[39] M. H. Chisholm, S. E. Brown-Xu, T. F. Spilker, Acc. Chem. Res., 48 (2015) 877-885.

[40] G. Li, P. Hao, J. Shen, T. Yu, H. Li, Y. Fu, Inorg. Chem., 55 (2016) 11342-11347.

[41] J. Zhang, Z. J. Li, Y. Kang, J. K. Cheng, Y. G. Yao, Inorg. Chem., 43 (2004) 8085-8091. 